\title{
Electron Transport in Phosphorylating Mitochondria from Tetrahymena pyriformis Strain ST
}

\author{
By G. TURNER,* D. LLOYD AND B. CHANCE \\ Department of Microbiology, University College, Newport Road, \\ Cardiff, CFI ITA, and Johnson Research Foundation, Department of \\ Biophysics and Physical Biochemistry, University of Pennsylvania, \\ Philadelphia, Pennsylvania I9ror, U.S.A.
}

(Accepted for publication 20 Jamuary I97I)

\section{SUMMARY}

Mitochondria isolated from Tetrahymena pyriformis carried out oxidative phosphorylation with succinate and 2-oxoglutarate as substrates. Electron transport was inhibited by rotenone, piericidin $\mathrm{A}$, antimycin $\mathrm{A}$ and cyanide. Succinate-cytochrome $c$ and ferricyanide oxidoreductases were antimycin A sensitive. NADH-cytochrome $c$ and ferricyanide oxidoreductases were only partially inhibited by high concentrations of rotenone. Externally added NADH gave no oxygen uptake in the absence of artificial electron acceptors. The mitochondria contained haems $a, c$ and protohaem, and difference spectra revealed the presence of cytochromes $b, c, c_{1}$ and a pigment with an extinction maximum at $620 \mathrm{~nm}$. Steady-state and kinetic measurements of cytochrome components were made. Several kinetically distinct flavoprotein components were present. Kinetic measurements suggested that the reduced $620 \mathrm{~nm}$. component reacted sufficiently rapidly with molecular oxygen to have been the terminal oxidase.

\section{INTRODUCTION}

Mitochondria capable of oxidative phosphorylation were first isolated from Tetrahymena pyriformis strain GL by Kobayashi (1965). In this and in earlier studies (Ryley, 1952; Eichel, 1954) cytochrome oxidase activity was not detected when reduced mammalian cytochrome $c$ was used as substrate for cell-free preparations; neither was the $\alpha$-band of cytochrome oxidase demonstrated spectroscopically.

The present work was undertaken to obtain a better understanding of electron transport in phosphorylating mitochondria isolated from Tetrahymena. Strain ST has been used previously in studies of mitochondrial DNA (Suyama \& Eyer, 1968), and the method used here for isolation of mitochondria is based on those of Kobayashi (1965) and Suyama \& Preer (I965). A preliminary account of some of this work has previously been published (Turner, Lloyd \& Chance, 1969).

\section{METHODS}

Maintenance growth, and harvesting of the organism. Tetrahymena pyriformis strain ST (kindly provided by Dr Y. Suyama, Department of Biology, University of Penn-

* Present address: Department of Bacteriology, The Medical School, University Walk, Bristol, BS8 ITD. 
sylvania) was maintained, grown and harvested as described previously (Lloyd, Brightwell, Venables, Roach \& Turner, I97I). Volumes of culture up to 201 . were used for the preparation of mitochondria, and organisms were harvested in late exponential phase of growth ( 5 to $7 \times 10^{4}$ organisms $/ \mathrm{ml}$.).

Disruption of organisms. The organisms were washed once in preparation buffer consisting of $0.35 \mathrm{M}$-mannitol, $0.1 \%(\mathrm{w} / \mathrm{v})$ bovine serum albumin, $0.1 \mathrm{~mm}$-EGTA (ethylene glycol-bis ( $\beta$-amino-ethyl ether) $N, N^{\prime}$-tetraacetic acid), Io mM-tris- $\mathrm{HCl}$, $\mathrm{pH} 7 \cdot 2$, and resuspended in 5 vol. of this buffer (approximately ro $\mathrm{mg}$. protein $/ \mathrm{ml}$.). The suspension was homogenized in a $50 \mathrm{ml}$. Kontes (Vineland, New Jersey, U.S.A.) tight fitting (type B plunger) glass hand-homogenizer in ice, until over $90 \%$ of the cells were broken ( 20 to 30 strokes).

Preparation of mitochondrial fractions. All operations were carried out at $4^{\circ}$. The whole homogenate was transferred to $50 \mathrm{ml}$. centrifuge tubes and centrifuged at $300 \mathrm{~g}$ for $5 \mathrm{~min}$. to remove whole organisms and pellicles. The supernatant was recentrifuged at $7000 \mathrm{~g}$ for $10 \mathrm{~min}$. The resulting pellet consisted of a small amount of tightly packed reserve material at the bottom of the tube, a cream-coloured layer of mitochondria, and a loosely packed white layer above this consisting of cell membranes, cilia and possibly lysosomes and peroxisomes. The supernatant (containing microsomal and 'soluble' fractions) was carefully removed and most of the upper white layer with it. Five vol. of preparation buffer were added to the residue and shaken gently to remove the mitochondrial fraction, which was resuspended and recentrifuged at $7000 \mathrm{~g}$ for ro min. The separation procedure was repeated and the mitochondrial fraction retained (approx. Io $\mathrm{mg}$. protein/l. of culture).

Analytical methods. Polarograph measurements of oxygen uptake by mitochondrial suspensions were made with an oxygen electrode (Lloyd \& Brookman, 1967). Respiratory control ratios and $\mathrm{ADP} / \mathrm{O}$ ratios were calculated by the method of Chance \& Williams (1956). Difference spectra were traced with a Cary model I4 split-beam spectrophotometer fitted with a 0 to $0 \cdot 1$ extinction slide wire. Low temperature spectra were obtained using a split-beam spectrophotometer (Yang \& Legallais, 1954) with a liquid $\mathrm{N}_{2}$ attachment (Chance, 1957). Steady-state reduction levels of electron transport components were measured using a dual wavelength spectrophotometer (Chance, I95I). Unless otherwise stated, the buffer used in all analytical experiments contained $0.35 \mathrm{M}$-mannitol, 0.I mM-EGTA, Io $\mathrm{mm}-\mathrm{KCl}$, Io $\mathrm{mM}$ phosphate, and $0.1 \%(\mathrm{w} / \mathrm{v})$ bovine plasma albumin at $\mathrm{pH} 7 \cdot 2$. Rapid reaction measurements of the reoxidation of substrate-reduced electron transport components in whole mitochondria were made using the regenerative flow apparatus of Chance (1954) fitted with fluorometric and dual wavelength measuring facilities. Briefly, the method involves mixing an anaerobic mitochondrial suspension with oxygenated buffer, after which the mixture is driven rapidly through the light path of a dual wavelength spectrophotometer or fluorometer. The reoxidation of an electron transport component is thus observed a short time after initiation of the reaction, and the proportion of component oxidized after this time is recorded using a storage oscilloscope. Oxidation of the anaerobic mitochondrial suspensions was achieved by addition of $16 \mu \mathrm{M}-\mathrm{O}_{2}$ in the form of oxygenated buffer, and reduction by respiration of the mitochondria in the presence of ro mM-succinate and $2 \mu \mathrm{M}$-carbonyl-cyanide $m$-chlorophenylhydrazone (CCCP) until state 5 was obtained (anaerobic). The path length of the observation window was $6 \mathrm{~mm}$. in all cases and the temperature $25^{\circ}$. The upper oscilloscope trace (see Results) 
indicates the syringe velocity, and the lower trace the spectrophotometric recording of the reaction. The time taken for the flow to travel from the mixing point of suspension and buffer to the observation window is referred to as $t_{\text {inj }}$. Values for $k_{1}$ are calculated after noting how far the reaction has gone towards completion once a steady flow is obtained, i.e. after time $=t_{\text {ind }}$. Then

where

$$
k_{1}=\frac{2 \cdot 3}{t_{\text {inj }}} \log \frac{D_{2}}{D_{1}}
$$

$$
\frac{D_{2}}{D_{1}} \text { is the ratio of } \frac{\text { Concentration of reduced cytochrome at time zero }}{\text { Concentration of reduced cytochrome after } t_{\mathrm{m}}} \text {. }
$$

Pyridine haemochrome derivatives were prepared according to the method of Falk (I964). Protein was measured by the method of Lowry, Rosebrough, Farr \& Randall (I95I), with bovine plasma albumin as a standard.

Enzyme assays. NADH-cytochrome $c$ reductase $\left(\mathrm{NADH}_{2}\right.$ :cytochrome $c$ oxidoreductase EC 1.6.2.1) was assayed according to the method of Mahler (1955). Succinate-cytochrome $c$ oxidoreductase was assayed in a similar way but using $0.1 \mathrm{M}-$ sodium succinate in the reaction mixture. When required, electron transport inhibitors (rotenone and antimycin A) were added as methanolic solutions.

Electron microscopy. Whole organisms were fixed in $2 \%(\mathrm{w} / \mathrm{v})$ unbuffered potassium permanganate for $2 \mathrm{~h}$. at $4^{\circ}$ (Luft, 1956), dehydrated via an alcohol series and embedded in Araldite. For mitochondrial preparations, the fixative contained $0.35 \mathrm{M}$ sucrose. Ultra-thin sections were cut with an LKB Ultramicrotome, and floated on to copper grids. Negative staining was done with $\mathrm{I} \%(\mathrm{w} / \mathrm{v})$ potassium phosphotungstate, $\mathrm{pH} 6.8$. The specimens were examined and photographed in an A.E.I. EM 6 operating at $60 \mathrm{kV}$.

Materials. ADP, ATP, NAD, NADH, cytochrome $c$ (horse heart type III), antimycin A, 2-oxoglutarate, malate, oligomycin and EGTA were obtained from Sigma Chemical Co., St Louis, Missouri, U.S.A. Bovine Albumin Powder (fraction V from bovine plasma) was obtained from Armour Pharmaceutical Co. Ltd, Eastbourne. Rotenone was a gift from Professor L. Crombie, Department of Chemistry, University College, Cardiff, and piericidin A was from Dr Karl Folkers, Stanford Research Institute, Menlo Park, California, U.S.A.

\section{RESULTS}

Electron Microscopy. Isolated mitochondria (Pl. I, fig. I) suffered little apparent structural damage when compared with the mitochondria within the intact organism (P1. I, fig. 2). In sections the inner and outer membranes are clearly distinguishable. The extent of the tubular cristae is readily seen in negatively stained preparations of isolated mitochondria (PI. I, fig. 3) as the phosphotungstate penetrates the intermembrane space and fills the cristae tubules, making them electron-dense.

Oxidation of substrate by isolated mitochondria. Table I shows typical oxidation rates obtained. Succinate, 2-oxoglutarate and DL-lactate were the only substrates tested which gave high oxygen uptake rates. Oxidation rates of isocitrate and of glutarate were increased on adding low concentrations of malate. NADH oxidation was undetectable in both intact and sonicated mitochondria. Respiratory control could be demonstrated for 2-oxoglutarate and succinate but not for other substrates 


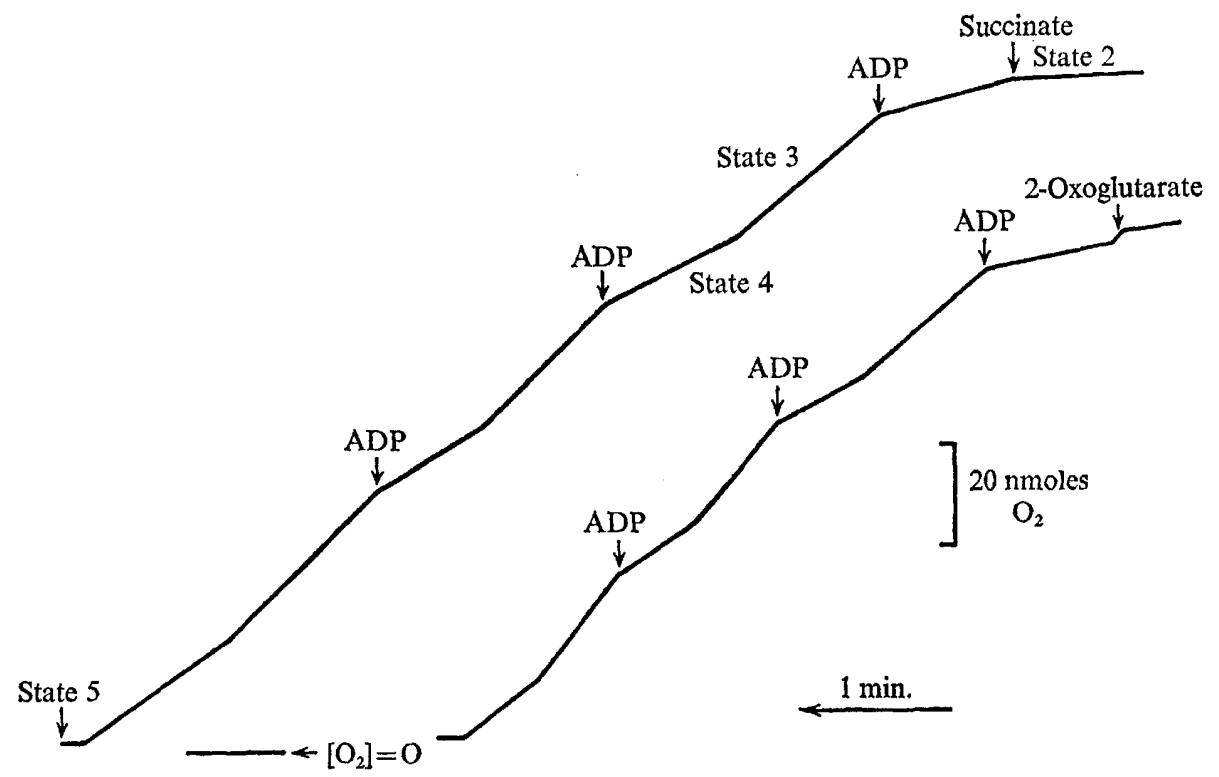

Fig. I. Respiratory control in isolated mitochondria. The oxygen electrode traces are examples of those obtained with $10 \mathrm{mM}$-succinate and $10 \mathrm{mM}-2$-oxoglutarate as substrates (each ADP addition was 80 nmoles). Temperature of incubation $25^{\circ}$. The range of ADP/O values and respiratory control (RC) ratios obtained in four experiments were as follows:

ADP/O R.C.

$\begin{array}{lll}\text { 2-Oxoglutarate } & I \cdot 3 \text { to } 2 \cdot 3 & I \cdot 2 \text { to } 2 \cdot 2 \\ \text { Succinate } & 0.8 \text { to } I .5 & I \cdot I \text { to } I .6\end{array}$

\section{Table I. Oxidation of substrates by mitochondria isolated from Tetrahymena pyriformis}

Oxygen uptake was followed polarographically at $25^{\circ}$ with a mitochondrial suspension containing $0.5 \mathrm{mg} . / \mathrm{ml}$. protein. Rates of $\mathrm{O}_{2}$ uptake shown are in the presence of substrate and 80 nmoles of ADP (state 3) after subtraction of endogenous respiration rate (no added substrate).

\section{Substrate}

Tris-2-oxoglutarate

Sodium succinate

Sodium DL-lactate

Sodium citrate

Sodium isocitrate + sodium malate

Sodium aspartate + sodium malate

Sodium malate + sodium malate sarcosine

Sodium $\alpha$-glycerophosphate

Ethanol

Sodium glutamate + sodium malate NADH

\section{Concentration (mM)}

9

9

9

9

0.9

9

0.9

0.9

9

0.9

9

5

2

0.9

$0 \cdot 1$
Specific activity (nmoles/min./mg. protein) 
tested. Typical traces are shown in Fig. I together with a range of ADP/O and respiratory control values calculated from four experiments. Phosphorylation cycles could be repeated until the oxygen in the reaction vessel was exhausted.

Inhibition of oxidation by antimycin $A$, rotenone, piericidin $A$ and cyanide. Inhibition curves for antimycin A, rotenone and piericidin A are shown in Fig. 2. Tetrahymena mitochondria were a I000-fold less sensitive to antimycin $\mathbf{A}$ and rotenone inhibition than rat liver mitochondria (Slater, 1967) but only threefold less sensitive to piericidin A (Hall et al. 1966). Cyanide (I mM) gave $99 \%$ inhibition of state 3 respiration with both 2-oxoglutarate and succinate.

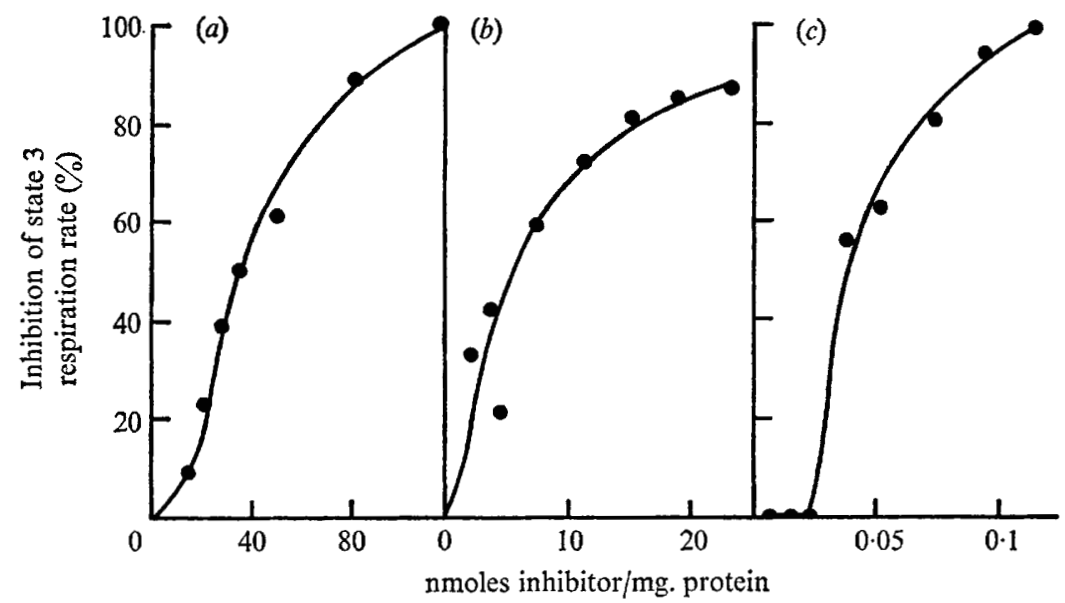

Fig. 2. Inhibition of electron transport by (a) antimycin $\mathbf{A},(b)$ rotenone and $(c)$ piericidin $\mathbf{A}$ in isolated mitochondria. Inhibitors were added as methanolic solution to suspensions of mitochondria respiring in the presence of $9 \mathrm{~mm}$-substrate and $0.1 \mathrm{~mm}-\mathrm{ADP}$ at $25^{\circ}$. For inhibitors acting at or near site I (rotenone and piericidin A) the substrate was 2-oxoglutarate, and for site II inhibitor (antimycin A), succinate. Methanol controls showed no inhibitory effect with either substrate.

Table 2. Reduction of mammalian cytochrome $c$ and ferricyanide by NADH and by succinate in the presence of mitochondria isolated from Tetrahymena pyriformis

The assay mixture ( $\mathrm{I} \mathrm{ml}$.) contained $0.3 \mathrm{mg}$. cytochrome $c$ or $3 \mathrm{~mm}$-ferricyanide, I0 mM$\mathrm{KCN}$ and mitochondria (0.1 to $0.3 \mathrm{mg}$. protein) in preparation buffer. The reactions were started by adding Io mM-succinate or O.I mM-NADH, blanks contained no substrates, cytochrome $c$ reduction was followed at $550 \mathrm{~nm}$., ferricyanide reduction at $400 \mathrm{~nm}$. Inhibitors were added as methanolic solutions. Figures in parenthesis indicate extent of inhibition by an equal volume of methanol. Results typical of those obtained with four different mitochondrial suspensions. Specific activities expressed as cytochrome $c$ or ferricyanide reduced. Temperature of incubations $18^{\circ}$.

Enzyme system

Succinate-cytochrome $c$ oxidoreductase $+\operatorname{antimycin} \mathbf{A}$

Succinate-ferricyanide oxidoreductase + antimycin A

NADH-cytochrome $c$ oxidoreductase trotenone

NADH-ferricyanide oxidoreductase + rotenone
Specific activity (nmoles/min./mg. protein)

$$
\mathrm{I} 2 \cdot 8
$$

(1460 nmoles $/ \mathrm{mg}$. protein)

$240 \cdot 0$

(I460 nmoles/mg. protein)

$37 \cdot 8$

(500 nmoles/mg, protein)

520.0

(500 nmoles/mg. protein)
Inhibition

(\%)

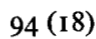

$$
\begin{gathered}
84(15) \\
- \\
38(7) \\
- \\
19(5)
\end{gathered}
$$$$
\text { M I C } 65
$$ 
Reduction of artificial electron acceptors. Externally added mammalian cytochrome $c$ and ferricyanide were both reduced by isolated mitochondria in the presence of either NADH or succinate. Table 2 shows activities measured as saturating substrate concentrations, together with the inhibitory effects of rotenone and antimycin A. NADH-cytochrome $c$ and NADH-ferricyanide oxidoreductases were only partially inhibited by rotenone in 'intact' mitochondria at a concentration which completely inhibited 2-oxoglutarate oxidation, suggesting that these oxidoreductions did not involve the respiratory chain which is presumably located in the inner mitochondrial

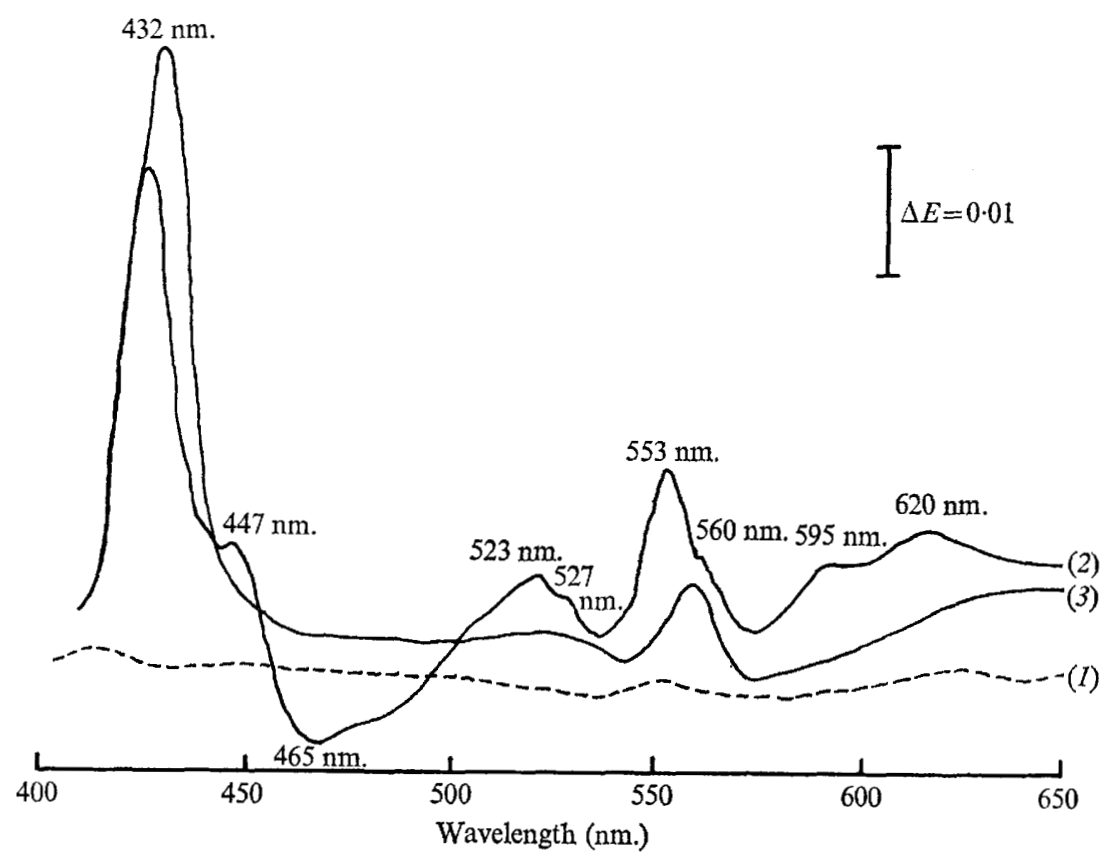

Fig. 3. Difference spectra (reduced minus oxidized) of Tetrahymena mitochondria. The suspension of mitochondria contained $3.0 \mathrm{mg}$. protein $/ \mathrm{ml}$. (path length $10 \mathrm{~mm}$.). Curve $(I)$ represents the baseline (oxidized minus oxidized). Curve (2) was obtained after addition of ro mM-succinate to one of the cuvettes and exhaustion of dissolved $\mathrm{O}_{2}$ (state 5). Curve (3) was obtained following addition of 360 nmoles of antimycin $\mathrm{A}$ and reaeration of both cuvettes.

Table 3. NADH-cytochrome c oxidoreductase activity in sonicated mitochondria

A suspension of mitochondria in buffer (Io $\mathrm{mg}$. protein $/ \mathrm{ml}$.) was sonicated for I min. using an MSE $50 \mathrm{~W}$ sonicator at full output. Activities were measured at $18^{\circ}$ as described in Table 2 under conditions where neither cytochrome $c$ nor NADH become rate-limiting over the range of cytochrome $c$ reduction followed.

Specific activities (nmoles/min./mg. protein)

\begin{tabular}{|c|c|c|c|}
\hline & \\
\hline & Initial rate & $\begin{array}{l}\text { Rate after I } \\
\text { min. of } \\
\text { reaction }\end{array}$ & $\begin{array}{c}\text { Rate with } \\
\text { rotenone } \\
\text { added } \\
\text { (150 nmoles/mg } \\
\text { protein) }\end{array}$ \\
\hline $\begin{array}{l}\text { Unsonicated mitochondria } \\
\text { Sonicated mitochondria }\end{array}$ & $\begin{array}{l}45 \cdot 8 \\
93 \cdot 3\end{array}$ & $\begin{array}{l}3 I \cdot 7 \\
44 \cdot I\end{array}$ & $\begin{array}{l}25 \cdot 8 \\
30 \cdot 0\end{array}$ \\
\hline
\end{tabular}


membrane. In sonicated mitochondria, a higher NADH-cytochrome $c$ reductase activity was observed, but this activity appeared to be unstable and declined after several minutes. Addition of excess rotenone to the assay system revealed similar rotenone-insensitive activity in both sonicated and unsonicated preparations (Table 3 ). The results suggest that rotenone-sensitive activity is associated with the respiratory chain, to which externally added NADH is inaccessible in intact mitochondria, while in sonicated mitochondria this inner membrane activity is rapidly lost. Both succinatecytochrome $c$ and ferricyanide reductase activities were inhibited by addition of antimycin $\mathbf{A}$.

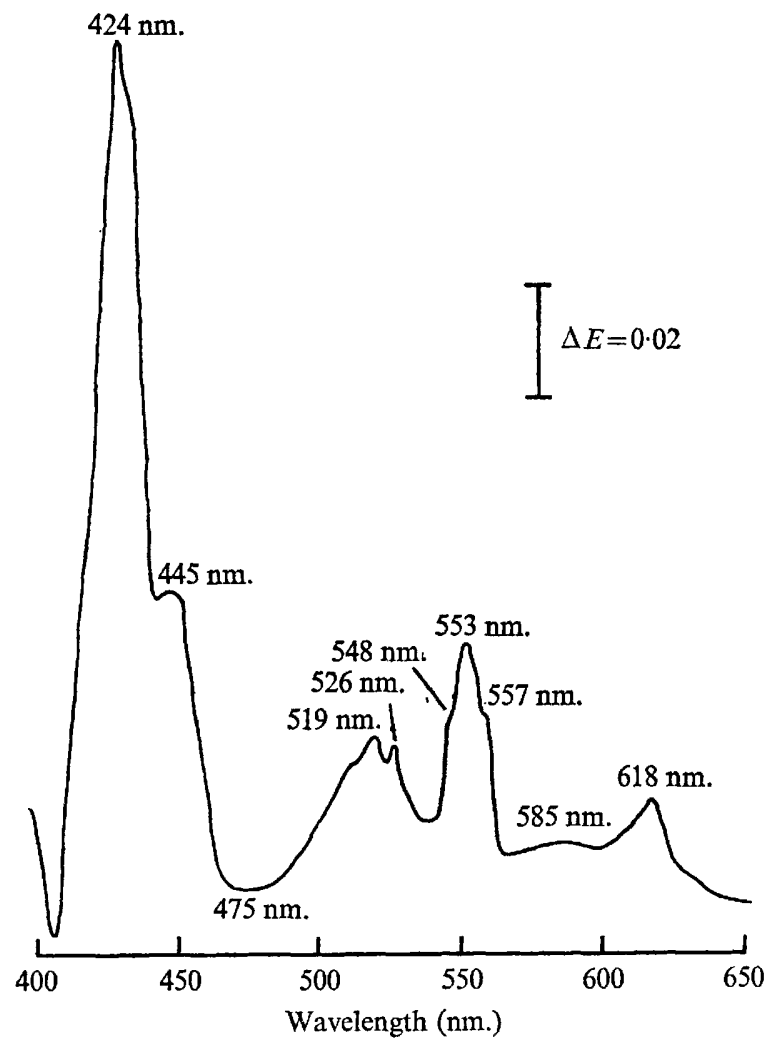

Fig. 4. Low temperature difference spectrum of Tetrahymena mitochondria. The mitochondrial suspension contained $6.2 \mathrm{mg}$ protein $/ \mathrm{ml}$. Reduction was achieved by addition of excess sodium dithionite and oxidation by aeration. The samples were introduced into precooled cuvettes (path length $2 \mathrm{~mm}$.) and immediately cooled by immersion in liquid $\mathrm{N}_{2}$.

Extinction spectra of mitochondria. Extinction maxima in difference spectra at 560 , 527 and $432 \mathrm{~nm}$. (Fig. 3) represented the $\alpha, \beta$ and $\gamma$ bands of cytochrome $b$, while those at 553 and $523 \mathrm{~nm}$. indicated the presence of a $c$-type cytochrome. The classical extinction maximum for cytochromes $\left(a+a_{3}\right)$ at $605 \mathrm{~nm}$. was not observed although a $\gamma\left(a_{3}+a\right)$ extinction was evident at $447 \mathrm{~nm}$. The flavoprotein-non-haem iron trough was often observed at 465 to $470 \mathrm{~nm}$. but not identified. Addition of antimycin A (sufficient for $50 \%$ inhibition of state 3 respiration) followed by reaeration of the reduced suspension resulted in reoxidation of the $620 \mathrm{~nm}$. band and of cytochrome $c$, 
while cytochrome $b$ remained reduced, indicating the presence of an antimycin Asensitive site between cytochromes $b$ and $c$. Part of the flavoprotein was reoxidized despite the reduction of cytochrome $b$, suggesting the presence of a flavoprotein oxidase(s).

Fig. 4 shows a low temperature difference spectrum (dithionite reduced minus oxidized) of the $\alpha$-region. There was a peak shift of 2 to $3 \mathrm{~nm}$. towards the blue end of the spectrum for all components other than flavoprotein, which appears at $475 \mathrm{~nm}$. A minor component was present at $585 \mathrm{~nm}$., probably corresponding to the $595 \mathrm{~nm}$ component often observed in room temperature spectra. The individual components

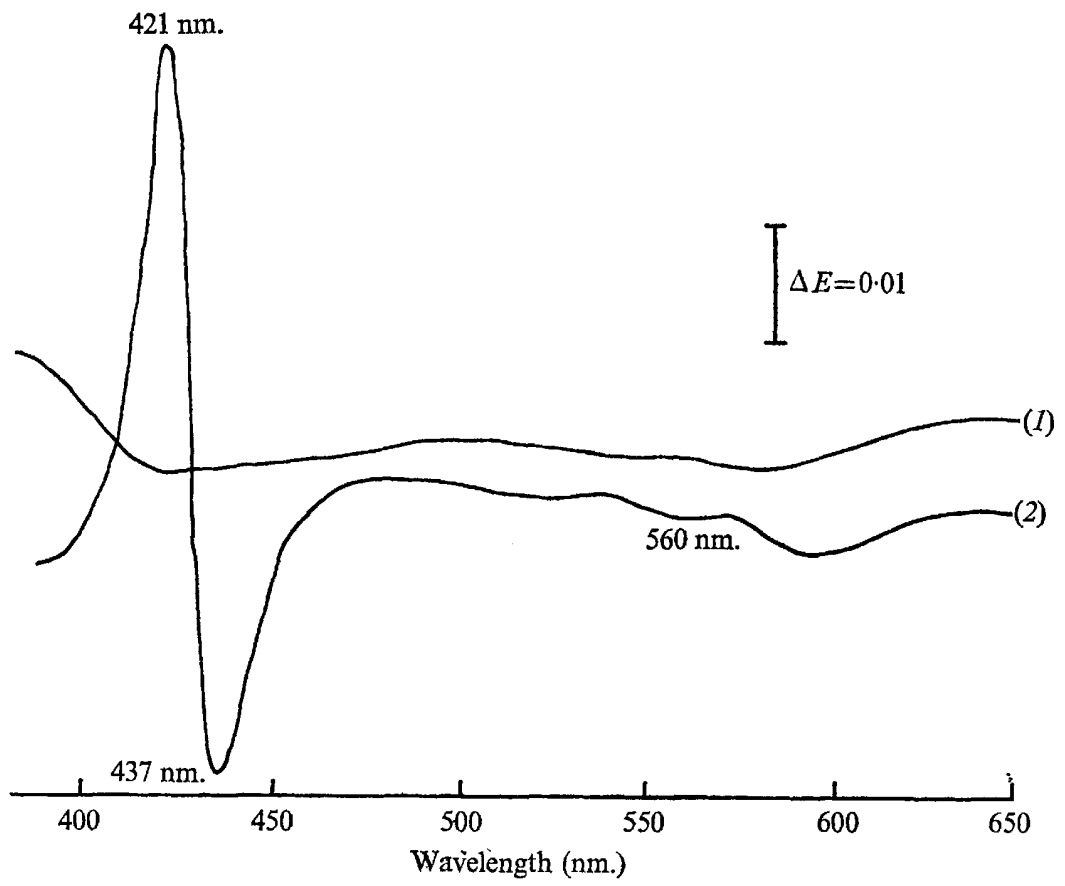

Fig. 5. Carbon monoxide spectrum of mitochondria isolated from Tetrahymena. Each cuvette (path length $10 \mathrm{~mm}$.) contained mitochondrial suspension $(2.5 \mathrm{mg}$. $/ \mathrm{ml}$.). The suspensions were reduced by addition of $10 \mathrm{~mm}$-succinate to each cuvette, allowing time for exhaustion of dissolved oxygen. After recording a baseline (succinate reduced minus succinate reduced) (I) CO was passed through the test suspension, and the $\mathrm{CO} /$ reduced minus reduced spectrum was recorded (2).

were more sharply resolved than at room temperature, and a shoulder at $548 \mathrm{~nm}$. indicated the presence of cytochrome $c_{1}$.

$\mathrm{CO}$-spectrum. In order to characterize further the cytochrome oxidase, the COreduced minus reduced difference spectrum of whole mitochondria was determined (Fig. 5). The preparation showed the spectrum, characteristic of cytochrome oxidase (Chance, 1957), although cytochrome $b$ purified from Tetrahymena also reacts with CO (Yamanaka, Nagata \& Okunuki, 1967).

Pyridine haemochrome derivatives. Pyridine haemochrome derivatives were prepared from whole mitochondria in order to characterize the haems present. Fig. 6 shows the spectra of the derivatives (dithionite reduced minus ferricyanide oxidized). Peaks at $587 \mathrm{~nm}$., $557 \mathrm{~nm}$., $527 \mathrm{~nm}$., and 55I, $523 \mathrm{~nm}$. correspond to the derivatives of 


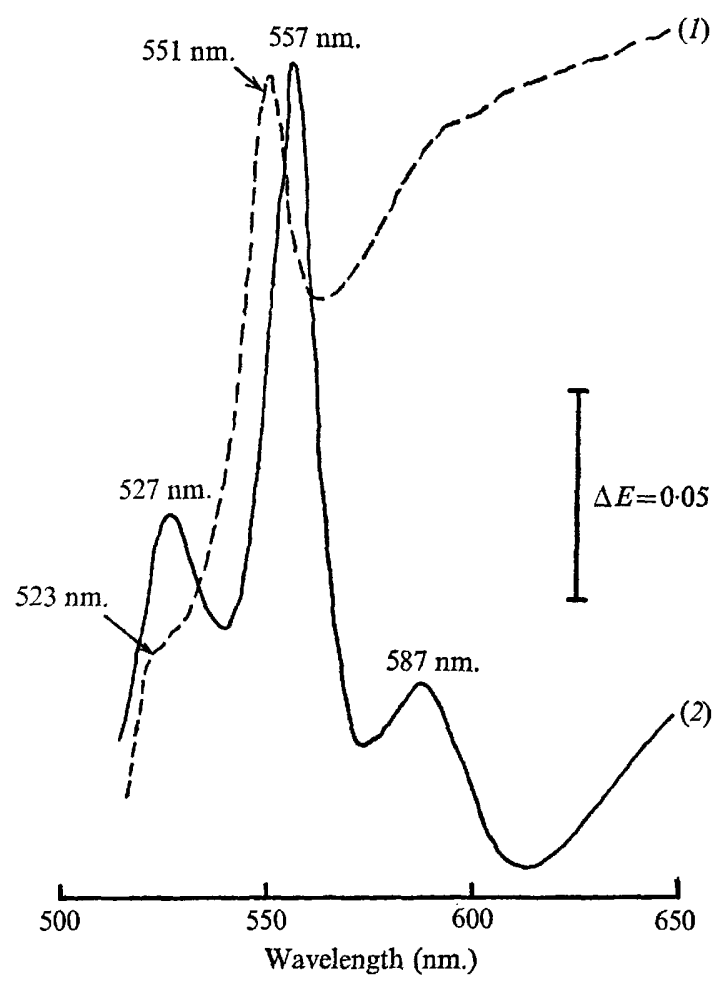

Fig. 6. Difference spectra for pyridine haemochrome derivatives. The extract containing haem $a$ and protohaem (Falk, 1964) was resuspended in distilled water, as was the pellet obtained after extraction (containing haem $c$ ). The difference spectrum of each fraction was obtained after addition of pyridine ( $\mathrm{I} \mathrm{ml}$.) and $\mathrm{N}-\mathrm{NaOH}(0.5 \mathrm{ml}$.) to the preparations $(4.5 \mathrm{ml}$.). To one cuvette I $\mathrm{mg}$. of ferricyanide was added, and to the other I $\mathrm{mg}$. of dithionite. (I) Haem $c$, (2) haem $a+$ protohaem.

\section{Table 4. Steady-state levels of reduction of electron transport components in mitochondria isolated from Tetrahymena pyriformis}

One hundred per cent reduction of a component taken as anaerobic reduction level minus level in the absence of exogenous substrate (state 5-state 2). ADP concentration was 0.I mM. Absence of a figure indicates that if any reduction occurred it was below the level of detection. No reduction of the $620 \mathrm{~nm}$. absorbing species $(620-650 \mathrm{~nm}$.) was detectable in states 3 or 4 with any of the substrates tested, and no extra reduction of this pigment was seen on adding dithionite to anaerobic suspensions. Temperature of incubation $25^{\circ}$.

Substrate

Electron transport component

Wavelength pair

(nm.)

Reduction state $4(\%)$

Reduction state $3(\%)$

Not reduced in state

5 but reduced by excess dithionite $\%$

\begin{tabular}{|c|c|c|c|c|c|c|c|}
\hline \multicolumn{2}{|c|}{ Io mM-Succinate } & \multicolumn{3}{|c|}{ Io mM-2-Oxoglutarate } & \multicolumn{3}{|c|}{ Io mM-Pyruvate } \\
\hline Cyt $b$ & Cyt $c$ & NAD & Cyt $b$ & Cyt $c$ & NAD & Cyt $b$ & Cyt , \\
\hline $560-$ & $553-$ & $340-$ & $560-$ & $533-$ & $340-$ & $560-$ & $553 \cdots$ \\
\hline $\begin{array}{l}575 \\
35 \cdot 6\end{array}$ & 540 & $\begin{array}{l}374 \\
84 \cdot 5\end{array}$ & $\begin{array}{l}575 \\
29 \cdot 7\end{array}$ & 540 & $\begin{array}{l}374 \\
85\end{array}$ & $\begin{array}{l}575 \\
25\end{array}$ & 540 \\
\hline $22 \cdot 4$ & 一 & $72 \cdot 7$ & $21 \cdot 8$ & - & 76 & 10 & - \\
\hline 35.0 & - & 一 & $55^{\circ} 0$ & IO & - & 50 & IO \\
\hline
\end{tabular}


haem $a$, protohaem and haem $c$, respectively. These figures coincide with those observed for mammalian mitochondria (Falk, 1964). Thus although no cytochrome $a$ was seen in the $605 \mathrm{~nm}$. region of difference spectra (Fig. 3) it seems that haemia was present in Tetrahymena mitochondria.

Steady-state reduction of electron transport components. Reduction levels of electron transport components in suspensions of isolated mitochondria (Table'4) were measured after addition of $3 \mathrm{~mm}$ substrate with ADP exhausted (state 4), after addition of sub-

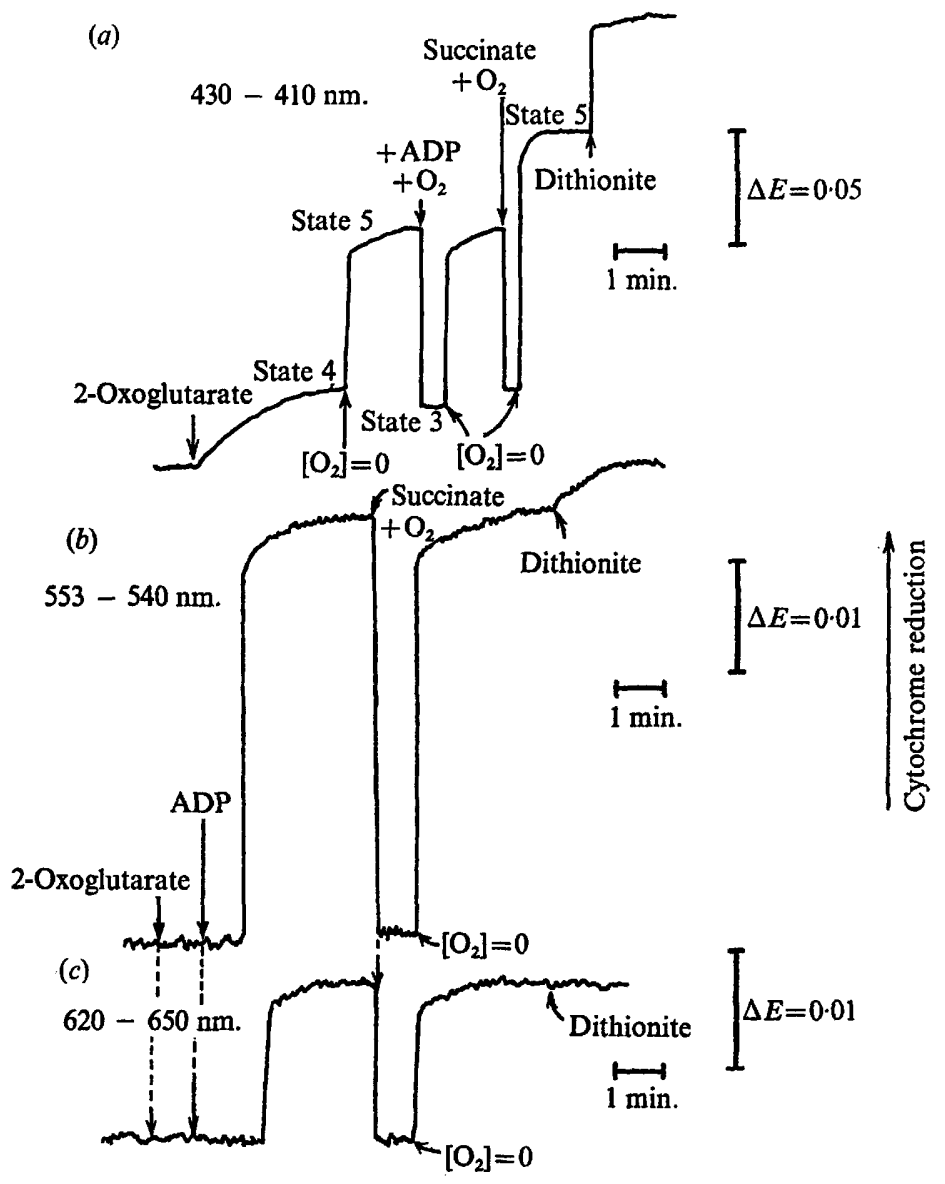

Fig. 7. Redox reactions of cytochromes $b, c$ and oxidase. Dual wavelength recordings (path length $10 \mathrm{~mm}$.). Temperature of incubation $25^{\circ}$, succinate and 2-oxoglutarate both Io mM, ADP o. I mM. Aeration was by shaking at points marked ' $+\mathrm{O}_{2}$ '. Dithionite ( $\mathrm{r}$ mg.) added to give complete reduction. (a) Cytochrome $b(5.2 \mathrm{mg}$ protein $/ \mathrm{ml}$.). (b) Cytochrome $c$ (6.4 mg. protein $/ \mathrm{ml}$.). (c) Cytochrome oxidase (6.4 mg. protein $/ \mathrm{ml}$.).

strate +ADP (state 3), and after exhaustion of the dissolved oxygen (state 5) (Chance \& Williams, 1956). To detect the proportion of component not reducible by substrate, sodium dithionite was added to suspensions in state 5. Throughout these experiments the wavelength pairs used were as follows: $620 \mathrm{~nm}$. absorbing species, 620 to $650 \mathrm{~nm}$.; cytochrome $b, 430-410 \mathrm{~nm}$.; cytochrome $c, 553-540 \mathrm{~nm}$.; NADH, $340-374 \mathrm{~nm}$. For cytochrome $b$ the $\gamma$-band was chosen for greater sensitivity, 
measurements at $560 \mathrm{~nm}$. were often interfered with by the $\alpha$-band of cytochrome $c$ $(553 \mathrm{~nm}$.). State 5 reduction for cytochrome $b$ by 2-oxoglutarate or by pyruvate was only $60 \%$ of that observed with succinate (Fig. 7). Cytochromes $c$ and $a$ were equally reduced with all three substrates. Endogenous respiration (washed mitochondria with no added substrate) gave a state 5 level of reduction similar to that observed for substrates other than succinate. Cytochrome $b$ was not completely reduced by substrate oxidation, as can be seen from the addition of dithionite. Cytochrome $c$ was $90 \%$ reduced and cytochrome $a$ fully reduced under these conditions. No reduction of cytochrome $c$ or the $620 \mathrm{~nm}$. pigment was observed in states 3 and 4. Comparable results were obtained by observing difference spectra (succinate reduced minus oxidized) at successive time intervals after addition of substrate to one cuvette (Fig. 8).

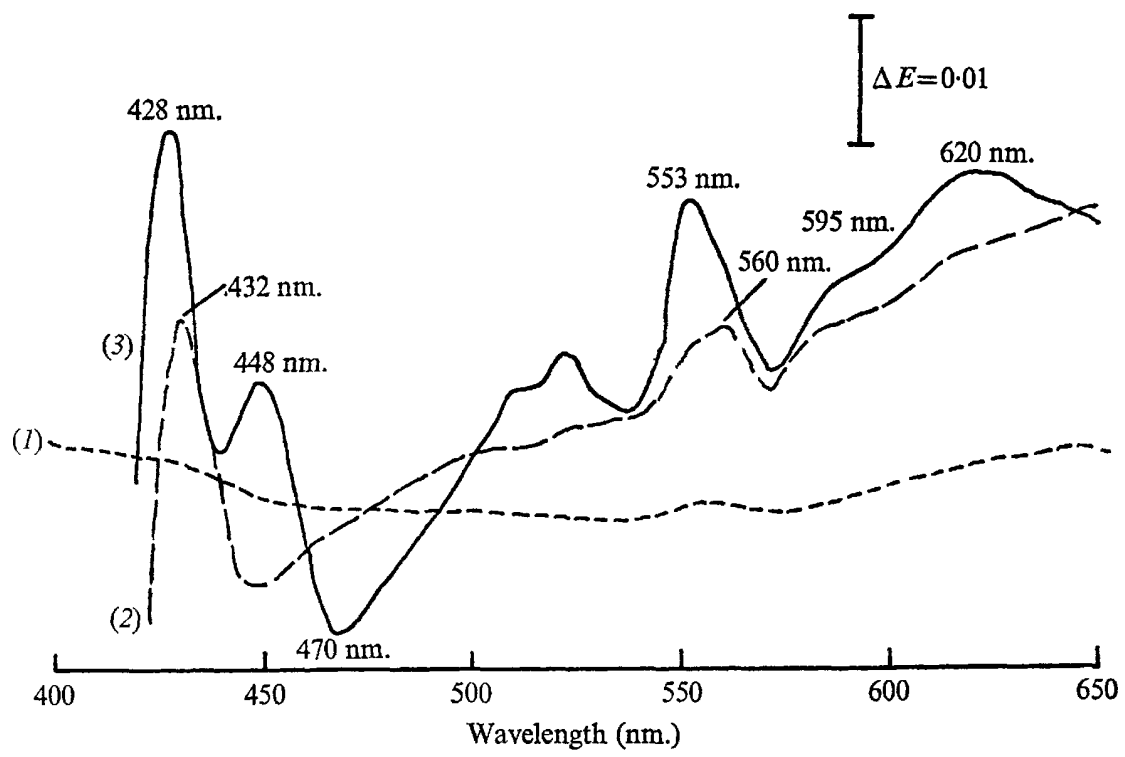

Fig. 8. Steady-state spectra of mitochondria isolated from Tetrahymena. The mitochondrial suspension contained $4 . \mathrm{r} \mathrm{mg}$. protein $/ \mathrm{ml}$. (path length $\mathrm{IO} \mathrm{mm}$.). Curve $(r)$, oxidized minus oxidized (baseline); curve (2), succinate reduced (state 4) minus oxidized ( $2 \mathrm{~min}$. after addition of $10 \mathrm{~mm}$-succinate); curve (3), $5 \mathrm{~min}$. after addition of succinate, anaerobic (state 5) minus oxidized (state 2 ). Temperature of incubation $18^{\circ}$.

With substrates other than 2-oxoglutarate and pyruvate (including succinate, DLlactate, citrate, malate) no steady-state reduction of NAD was observed, indicating that these substrates were either unable to gain access to the mitochondrial matrix, or were not NAD-linked.

With tightly coupled mitochondria respiring in the presence of succinate, 2-oxoglutarate or pyruvate, changes in steady-state levels of reduction of cytochrome $b$ and NAD were induced by addition of 0.1 mM-ADP, both components becoming more oxidized (Fig. 7; Table 4).

Addition of antimycin A to mitochondrial suspensions oxidizing succinate (sufficient for $50 \%$ inhibition of state 3 oxidation) resulted in an increase in the reduction level of cytochrome $b$ in state 3 from 22 to $52 \%$ of the state 5 level. Since reduction was 


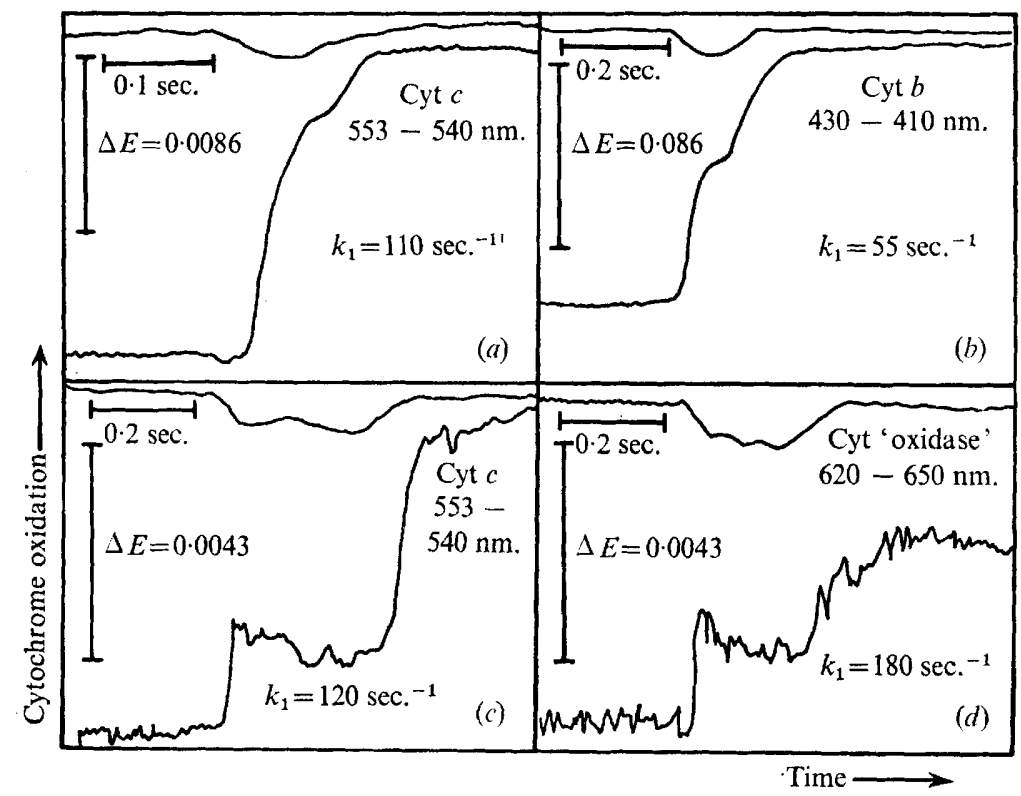

Fig. 9. Oscilloscope traces of reoxidation reactions of cytochromes $b, c$ and oxidase. $(a, b)$ $t_{\text {in }]}=14.2 \mathrm{msec}$., mitochondrial protein, II.2 mg. $/ \mathrm{ml}$. $(c, d) t_{\mathrm{inj}}=2.3 \mathrm{msec}$., mitochondrial protein, $5 \cdot 3 \mathrm{mg} . / \mathrm{ml}$.

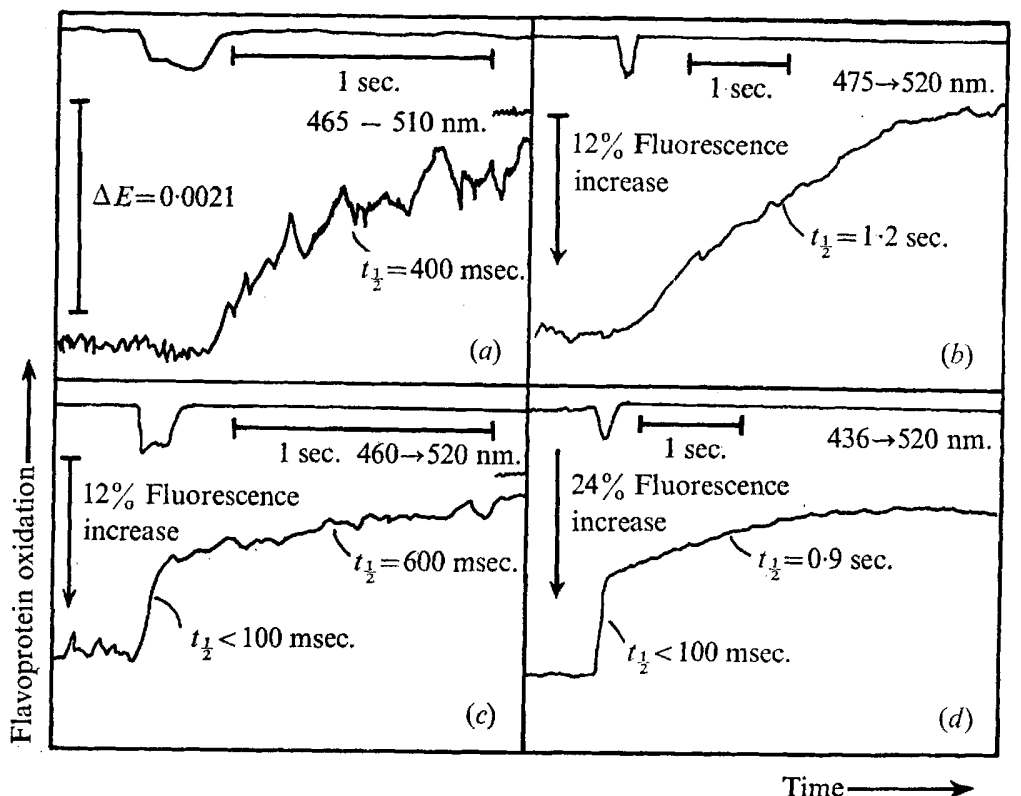

Fig. Io. Oscilloscope traces for the reoxidation reactions of flavoprotein, measured spectrophotometrically and fluorometrically. In traces $(a)$ and $(b)$ the reactions were so slow that no oxidation was detectable during the flow, and half-times are given for these 'stoppedflow' reactions. In traces $(c)$ and $(d)$ the reactions are more complex, and it appears that fast-reacting component(s) were present whose oxidation was completed during the flow. Temperature of incubation $25^{\circ} . t_{\text {inj }}=15.0 \mathrm{msec}$, mitochondrial protein $5.1 \mathrm{mg} . / \mathrm{ml}$. 
not $100 \%$, a leak of electrons past the partially inhibited site was indicated. Both cytochrome $c$ and $620 \mathrm{~nm}$. absorbing species remained fully oxidized.

Kinetics of cytochrome and flavoprotein reoxidation. All the following experiments were carried out on suspensions of mitochondria containing Io mM-succinate as substrate, and $2 \mu \mathrm{M}-\mathrm{CCCP}$ as uncoupling agent, with the regenerative flow apparatus of Chance (I954). When the respiring mitochondria had used up all the oxygen in the suspension, the state $5 \rightarrow$ state 3 (uncoupled) transition was measured following rapid mixing of the anaerobic suspension with oxygen-saturated buffer. After mixing, the final concentration of oxygen in the mitochondrial suspension was I $6 \mu \mathrm{M}$. Lowering of the added oxygen concentration to $3 \mu \mathrm{M}$ did not noticeably alter the reaction velocities of the components. The oscilloscope traces obtained are shown in Fig. 9 and 10 , together with the calculated $k_{1}$ values for pseudo first-order reactions. The data shown in Fig. 9 indicate that the velocity of oxidation of the $620 \mathrm{~nm}$. component was greater than the oxidation velocity of cytochrome $c$, which was greater than the oxidation velocity of cytochrome $b$.

Flavoprotein oxidation (Fig. 10) was measured spectrophotometrically ( 465 to $5 \mathrm{I} 0 \mathrm{~nm}$.) and fluorometrically (excitation at $436 \mathrm{~nm}$., $460 \mathrm{~nm}$. and $475 \mathrm{~nm}$., emission at $520 \mathrm{~nm}$.). Spectrophotometric measurements suggested a slowly reoxidizing component $\left(t_{\frac{1}{2}}=400 \mathrm{msec}\right.$.). Similarly, fluorometric measurements by excitation at 475 $\mathrm{nm}$. detected a slow reacting component only $\left(t_{\frac{1}{2}}=1200 \mathrm{msec}\right.$.). However, excitation at $460 \mathrm{~nm}$. and $436 \mathrm{~nm}$. indicated biphasic reactions, consisting of a very fast reacting component $\left(t_{\frac{1}{2}}=100 \mathrm{msec}\right.$.) and a more slowly reacting component(s) $\left(t_{\frac{1}{2}}=900 \mathrm{msec}\right.$., $436 \mathrm{~nm}$.; $t_{\frac{1}{2}}=600 \mathrm{msec}$., $460 \mathrm{~nm}$.). Since the oxidation of the fast component was completed during the flow (compare with oxidation of cytochrome $b$ in Fig. 9) it is apparent that this component(s) was able to react with oxygen faster than cytochrome $b$, and thus its reoxidation could not proceed via cytochrome $b$. Fluorometric measurements of flavoprotein oxidation are more reliable than spectrophotometric measurements, being less susceptible to interference from non-haem iron.

\section{DISCUSSION}

Oxidation of 2-oxoglutarate, together with demonstration of control with this substrate, and the presence of sites I and II as suggested by electron transport inhibitors, suggests that the NAD-linked electron transport pathway to oxygen was intact in isolated mitochondria. The slow oxidation of citrate, isocitrate and malate suggests a permeability barrier for these substrates. Although endogenous NAD underwent reduction on addition of 2-oxoglutarate and pyruvate to mitochondrial suspensions, externally added NADH was not oxidized. Rat liver mitochondria do not oxidize exogenous NADH (Lehninger, 1955), but mitochondria isolated from several eukaryotic micro-organisms, including Prototheca zopfii (Lloyd, 1965), Polytomella caeca (Evans \& Lloyd, 1966), Hartmanella castellanii (Lloyd \& Griffiths, 1968), Saccharomyces carlsbergensis (Ohnishi, Kawaguchi \& Hagihara, 1966) and Aspergillus niger (Watson \& Smith, 1967), are able to, making Tetrahymena unusual in this respect.

The pathways of electrons from succinate or NADH to added mammalian cytochrome $c$ may be similar to those in mammalian mitochondria. Thus although mammalian cytochrome $c$ is not reoxidized by the oxidase of Tetrahymena (Kobayashi, 
1965), it is able to act as an artificial electron acceptor in a similar manner to ferricyanide, possibly reacting with the electron transport chain in the region of Tetrahymena cytochrome $c$. Much of the NADH-cytochrome $c$ reductase activity is rotenone-insensitive and may be associated with an outer membrane pathway as is the case with mammalian mitochondria (Parsons, I966). Up to $40 \%$ of the NADH-cytochrome $c$ reductase activity is rotenone-sensitive, suggesting an inner membrane pathway via site $\mathrm{I}$. The partial rotenone sensitivity of NADH-cytochrome $c$ reductase is difficult to reconcile with the inability of intact mitochondria to oxidize NADH.

The most unusual feature of the cytochrome components as observed in difference spectra was the absence of a cytochrome oxidase band at $605 \mathrm{~nm}$. Tetrahymena mitochondria are the only ones of those yet studied which exhibit this feature. Eichel (1954), Kobayshi (1965), van de Vijver (1966) observed that homogenates or cell-free preparations of Tetrahymena pyriformis were unable to reoxidize reduced mammalian cytochrome $c$, and concluded that cytochrome oxidase was absent from Tetrahymena mitochondria. It appears that all organisms which possess cytochrome $\left(a+a_{3}\right)$ $(\alpha$-band $605 \mathrm{~nm}$.) are able to reoxidize reduced mammalian cytochrome $c$ (Lloyd, 1965; Ohnishi et al. 1966; Evans \& Lloyd, 1966; Watson \& Smith, 1967; Lloyd \& Griffiths, 1968). Pyridine haemochrome characterization of the component haems indicated the presence of haem $a$. It seems possible that a cytochrome oxidase was present which, though atypical, contained haem $a$. In addition, evidence provided by the kinetic studies suggested that the $620 \mathrm{~nm}$. component reacted with oxygen at a velocity greater than that of cytochromes $b$ and $c$.

Both inhibitor studies and kinetic data suggested the presence of a flavoprotein oxidase, since flavoprotein was reoxidized even in the presence of antimycin A, and at a greater velocity than cytochrome $b$.

The observation that the state 5 reduction level of cytochrome $b$ observed with other substrates was only $60 \%$ that with succinate suggested the presence of two pools of cytochrome $b$, one reducible by succinate alone:

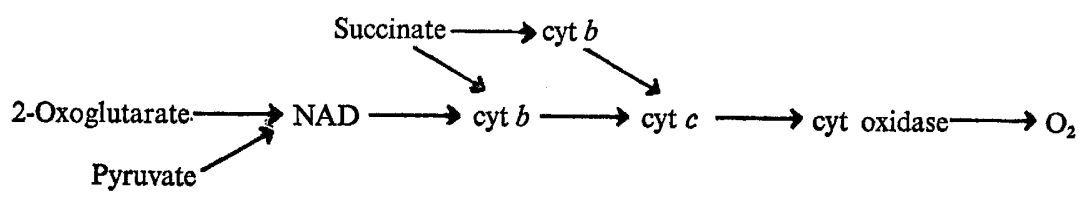

Reduction of cytochrome $c$ and oxidase could not be detected in states 3 and 4 . Chance \& Williams (1956) observed a stepwise sequence in the reduction levels of electron transport components during steady-state respiration, from NAD, the most reduced component, to cytochrome oxidase, the most oxidized. In state 4 coupled mitochondria exhibit some degree of inhibition of respiration at coupling sites, and on addition of ADP, cytochrome $a$ becomes more reduced and all other components more oxidized as the inhibitory effect is relieved. This 'crossover point' is observed between cytochromes $c$ and $a$ in rat liver mitochondria. The crossover point in Tetrahymena mitochondria was on the oxygen side of cytochrome $b$, indicating at least one coupling site between cytochrome $b$ and oxygen. Since cytochromes $c$ and $a$ were maximally oxidized in either steady state, no change was observed on addition or exhaustion of ADP. 
The authors wish to thank Professor D. E. Hughes for his interest, and Mr W. J. Henderson and $\mathrm{Mr}$ G. I. Roach for skilled assistance with electron microscope techniques. This work was done during the tenure of a Medical Research Council Studentship (G.T.).

\section{REFERENCES}

ChANCE, B. (195I). Rapid and sensitive spectrophotometry. III. A double beam apparatus. Review of Scientific Instruments 22, 634-638.

ChANCE, B. (1954). Regeneration and recirculation of reactants in the rapid flow apparatus. Discussions of the Faraday Society 17, 120-128.

Chance, B. (1957). Techniques for the assay of the respiratory enzymes. Methods in Enzymology 4, 273-329.

Chance, B. \& Wirliams, G. R. (1956). The respiratory chain and oxidative phosphorylation. Advances in Enzymology 17, 65-134.

EICHEL, H. J. (1954). Studies on the oxidation of succinic acid by cell-free homogenates of Tetrahymena pyriformis S and w. Journal of Biological Chemistry 206, 159-169.

Evans, D. A. \& LLOYD, D. (1966). Mitochondria from Polytomella caeca. Journal of Protozoology 13, Suppl. I19.

FALK, J. E. (1964). Porphyrins and Metalloporphyrins. New York: Elsevier Publishing Co.

hall, C., Wu, M., Crane, F., Takahashi, H., Tamura, S. \& Folkers, K. (1966). Piericidin A: a new inhibitor of mitochondrial electron transport. Biochemical and Biophysical Research Communications 25, 373-377.

Kobayashi, S. (1965). Preparation and properties of mitochondria from the ciliated protozoon Tetrahymena. Journal of Biochemistry (Tokyo) 58, 444-457.

LeHNINGER, A. L. (1955). Oxidative phosphorylation. Harvey Lectures 49, 176-215.

LLOYD,'D. (1965). Respiratory control in mitochondria isolated from the colourless algae Prototheca zopfii. Biochimica et biophysica acta 110, 425-426.

Lloyd, D., Brightwell, R., Venables, S. E., Roach, G. I. \& Turner, G. (1971). Subcellular fractionation of Tetrahymena pyriformis ST by zonal centrifugation: changes in activities and distribution of enzymes during the growth cycle and on starvation. Journal of General Microbiology 65, 209-223.

LLoYd, D. \& BROOKMAN, J. S. G. (1967). An oxygen electrode vessel. Biotechnology and Bioengineering 9, $271-272$.

LloYd, D. \& GrIfFITHS, A. J. (1968). The isolation of mitochondria from the amoeba Hartmanella castellanii Neff. Experimental Cell Research 5I, 29I-300.

Lowry, O. H., Rosebrough, N. J., FARr, A. L. \& RANDall, R. J. (1951). Protein measurement with the Folin phenol reagent. Journal of Biological Chemistry 193, 265-275.

LufT, J. H. (1956). Permanganate - a new fixative for electron microscopy. Journal of Biophysical and Biochemical Cytology 2, 799-801.

MAHLER, H. R. (1955). DPNH-cytochrome $c$ reductase (animal). Methods in Enzymology 2, 688-693.

OhNish, T., KaWAguchi, K. \& Hagihara, B. (1966). Preparation and some properties of yeast mitochondria. Journal of Biological Chemistry 241, 1797-1806.

PArsons, D. F. (1966). Ultrastructure and molecular aspects of cell membranes. Proceedings of the Canadian Cancer Research Conference 7, 193-246.

RYLEY, J. F. (1952). Studies on the metabolism of the protozoa. III. Metabolism of the ciliate, Tetrahymena pyriformis (Glaucoma pyriformis). Biochemical Journal 52, 483-492.

SLATER, E. C. (1967). Application of inhibitors and uncouplers for a study of oxidative phosphorylation. Methods in Enzymology ro, 48-57.

SUYAMA, Y. \& EYER, J. (1968). RNA synthesis in isolated mitochondria from Tetrahymena. Journal of Biological Chemistry 243, 320-328.

SuYAma, Y. \& Preer, J. R. Jun. (1965). Mitochondrial DNA from protozoa. Genetics 52, 105I-1058. TURNER, G., LLOYD, D. \& CHANCE, B. (1969). The electron transport chain of Tetrahymena pyriformis strain sT. Biochemical Journal Ix4, $91 \mathrm{P}$.

VAN DE VIJVER, G. (1966). Studies on the metabolism of Tetrahamena pyriformis GL. II. Some properties of the terminal oxidation. Enzymologia 3r, 382-391. 
WATSON, K. \& SMITH, J. E. (1967). Oxidative phosphorylation and respiratory control in mitochondria from Aspergillus niger. Biochemical Journal 104, 332-339.

Yamanaka, T., Nagata, Y. \& OKunuki, K. (I968). Purification and properties of cytochrome $c$-553 and cytochrome $b-560$ from Tetrahymena pyriformis. Journal of Biochemistry (Tokyo) 63, 753-760.

YANG, C. C. \& Legallais, V. (1954). A rapid and sensitive recording spectrophotometer for the visible and ultraviolet region. Review of Scientific Instruments 25, 80I-807.

\section{EXPLANATION OF PLATE}

Fig. I. Thin section of mitochondria isolated from Tetrahymena pyriformis, showing outer membrane (om), inner membrane (im), and cristae (cr). Fixed with $\mathrm{KMnO}_{4}$. Unstained. $\times 50,000$.

Fig. 2. Thin section of $T$. pyriformis; organism from a late exponential phase culture. Nucleus (n). mitochondria $(\mathrm{m})$, endoplasmic reticulum (er) and pellicle (p) are visible. Fixed with $\mathrm{KMnO}_{4}$. Unstained. $\times 26,500$.

Fig. 3. Mitochondria isolated from $T$. pyriformis. Unfixed and stained with $\mathrm{K}$ phosphotungstate. The stain has entered the intermembrane space and filled the tubes of the cristae. It has not entered the matrix (m). $\times 26,500$. 
Journal of General Microbiology, Vol. 65, No. 3

Plate I
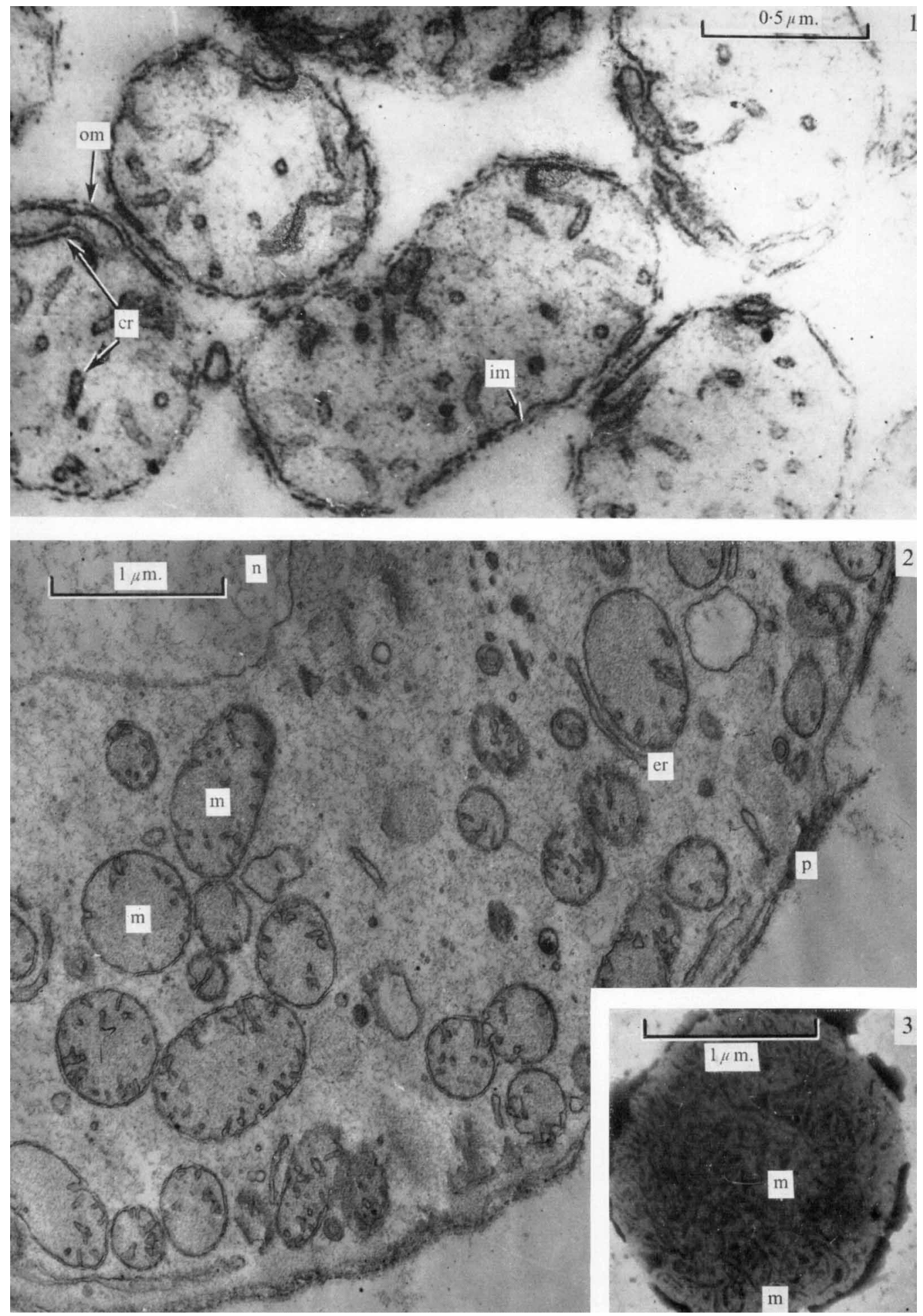

G. TURNER, D. LLOYD AND B. CHANCE

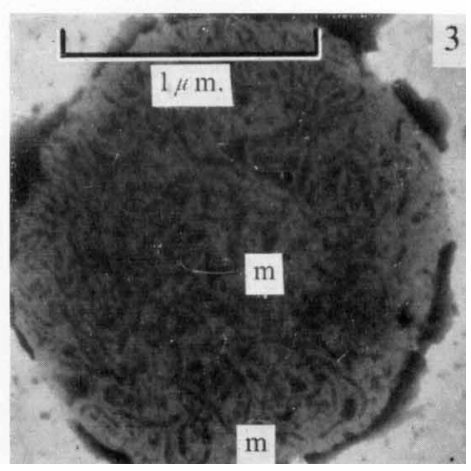

(Facing p. 374) 